\title{
High-risk human papillomavirus in the oral cavity of women with cervical cancer, and their children
}

\author{
Rajan Saini ${ }^{1 *}$, Tan P Khim', Sarah A Rahman', Mazian Ismail', Thean H Tang²
}

\begin{abstract}
Background: Association of High-risk Human Papillomavirus (HR-HPV) with oral cancer has been established recently. Detecting these viruses in oral cavity is important to prevent oral lesions related to them. The purpose of this study was to evaluate the prevalence of HR-HPV in the oral cavity of women with cervical cancer, and their children. A total of 70 women, previously diagnosed with cervical cancer, and 46 children of these women, born by vaginal delivery only, were selected for this study. Buccal swabs were collected from their oral cavity and HPV detection was carried out using Hybrid Capture 2 high-risk HPV (HC2 HR-HPV) detection system.

Results: Out of 70 women with cervical cancer, four (5.71\%) were found to be positive for HR-HPV in their oral cavity. No association of HR-HPV was found with sociodemographic profile, marital status, reproductive history, tobacco and alcohol usage, contraceptive pills usage, and presence of oral lesions ( $p>0.05$ ). Among children, HRHPV in the oral cavity was detected in only 1 of the 46 subjects examined (2.17\%). Clinically healthy oral mucosa, without any oral lesions, was observed in all the HR-HPV positive subjects.

Conclusion: The result of this study showed that there is low, if any, risk of HR-HPV infection in the oral cavity of women with cervical cancer. Further, our study suggests that there is very low risk for children of women with cervical cancer, to acquire and sustain HR-HPV in their oral cavity until childhood or adolescence.
\end{abstract}

\section{Background}

Human Papillomavirus (HPV) is an epitheliotropic, double stranded, circular DNA virus from Papovavirus family [1], which is found to infect cells in the basal layer of squamous epithelium [2]. Thus, infection caused by HPV is found in various body sites, such as anogenital tract, skin, conjunctiva, larynx, tracheobronchial mucosa, esophagus and oral cavity [3]. Over the years, more than 130 types of HPV have been identified according to the nucleotide sequence alignment of its open reading frames [4]. HPV is also classified as lowrisk and high-risk type, depending on its potential to cause malignant lesions such as cervical carcinomas [5]. In up to $92 \%$ of cervical malignancies, certain types of high-risk (HR) HPVs have been identified [6]. HR-HPV oncoproteins (E6 \& E7) act by disrupting the function of tumor suppressor genes ( $\mathrm{pRb} \& \mathrm{p} 53$ ), leading to excessive cell growth [1].

\footnotetext{
* Correspondence: rajan@kb.usm.my

'School of Dental Sciences, Universiti Sains Malaysia, Kubang Kerian, 16150, Kelantan, Malaysia
}

(c) 2010 Saini et al; licensee BioMed Central Ltd. This is an Open Access article distributed under the terms of the Creative Commons Attribution License (http://creativecommons.org/licenses/by/2.0), which permits unrestricted use, distribution, and reproduction in any medium, provided the original work is properly cited. independent risk factor for oral carcin Our recent study done in 105 oral squamous cell carcinomas (OSCC) affecting Malaysian population also found HPV to be significantly associated with OSCCs (P $<0.001$, OR $=4.3)[8]$. As seen in anogenital cancers, HR-HPV 16 is the most common HPV type found in oral carcinomas. Other oncogenic types seen in oral carcinomas include HPV 18, 31 and 33 [9]. Thus, it is imperative to detect HR-HPV in the oral cavity, as otherwise, these might cause benign or malignant HPV related oral lesions like papillomas and oral squmaous cell carcinomas in future. Several studies have been carried out to obtain the relationship of concurrent infection by HPV in cervical and oral sites [10,11].

Different methods have been used to detect HPV in concurrent infections giving varied results. PCR is used in many studies and it is known to be very sensitive in detection of HPV [12]. The Digene $\mathrm{HC}^{\circ}$ assay is United States Food and Drug Administration (USFDA) approved commercially available kit. $\mathrm{HC}^{\circ}$ assay is a nonradioactive, immuno-chemiluminescence method 
that is based on the hybridization of genotype-specific RNA probes to HPV genomic sequence. Compared with $\mathrm{PCR}, \mathrm{HC} 2^{\circ}$ has excellent clinical sensitivity, almost up to $100 \%$, as it shows only positive result when risk of disease progression exists. Studies have shown that $\mathrm{HC}^{\circ}$ is comparable to PCR and thus, it can be used as an adjunct or stand-alone test in HPV detection [13].

While the HPV related genital lesions are more frequently seen in adults, lesions like skin warts, oral and laryngeal papillomas are more frequently seen in children [14]. Further, the mode of viral transmission in children remains contentious. Several potential modes of transmission have been proposed for these pediatric HPV infections, which include non-sexual routes, like perinatal vertical transmission, auto- and hetero-inoculation, indirect transmission via fomites, and sexual ways, like sexual abuse $[15,16]$. Hajek suspected vertical transmission of juvenile onset recurrent respiratory papillomatosis (RRP), a relatively rare disease caused by HPV, from a mother to her child at birth, as early as 1956 [17]. Since then, several studies have been published giving results which vary from as low as $0 \%$ to as high as 80\% [18-20]. An argument against these earlier studies was that as the samples were taken at the time of, or soon after delivery, the HPV that was being detected in such samples may actually reflect a surface contamination of the infant with HPV infected maternal cells, rather than infection itself [21].

Therefore, the purpose of this study was to detect the prevalence of HR-HPV in the oral cavity of women with cervical cancer, and to evaluate the risk factors which contribute to its occurrence. Also, this study aimed to detect the existence of HR-HPV in children of the women with cervical cancer, for evaluation of vertical transmission of this virus, and to assess any associated risk factors.

\section{Results}

Demographic profile of women with cervical cancer, and their children

In total, 70 women diagnosed with cervical cancer and 46 children of these women, were recruited for this study. The demographic profile of the women and their children is given in Table 1 and Table 2 respectively. More than two-third of the women examined (68.5\%), were above 50 years of age, with the mean age of 55.21 years. Most of the subjects were Malay (82.9\%) and married (84.3\%). Most of the women did not have any tobacco or alcohol habits. For children, $82.6 \%$ were from 11 to 18 years of age, with the mean age of 14.78 years. There were more female children (54.3\%) than males (45.7\%). Most of the children did not have any tobacco or alcohol habits.
Table 1 Demographic profile of women with cervical cancer

\begin{tabular}{|c|c|c|}
\hline Variables & $n(n=70)$ & $\%$ \\
\hline \multicolumn{3}{|l|}{ Age range } \\
\hline 30-39 & 4 & 5.7 \\
\hline $40-49$ & 18 & 25.7 \\
\hline $50-59$ & 22 & 31.4 \\
\hline $60 \&$ above & 26 & 37.1 \\
\hline Mean \pm SD & $55.21 \pm 9.57$ & \\
\hline \multicolumn{3}{|l|}{ Race } \\
\hline Malay & 58 & 82.9 \\
\hline Chinese & 11 & 15.7 \\
\hline Indians & 1 & 1.4 \\
\hline \multicolumn{3}{|l|}{ Marital status } \\
\hline Married & 59 & 84.3 \\
\hline Single & 1 & 1.4 \\
\hline Divorce & 2 & 2.9 \\
\hline Remarried & 8 & 11.4 \\
\hline \multicolumn{3}{|l|}{ Age when married } \\
\hline$<18$ years old & 33 & 47.1 \\
\hline$>18$ years old & 37 & 52.9 \\
\hline \multicolumn{3}{|l|}{ Number of children } \\
\hline$<5$ & 26 & 37.1 \\
\hline$>5$ & 44 & 62.9 \\
\hline \multicolumn{3}{|l|}{ Habits } \\
\hline Tobacco & 3 & 4.3 \\
\hline Alcohol & 4 & 5.7 \\
\hline \multicolumn{3}{|c|}{ Pregnancy and contraception } \\
\hline Pregnant & 2 & 2.9 \\
\hline OCP usage & 24 & 34.3 \\
\hline
\end{tabular}

Table 2 Demographic profile of children of women with cervical cancer

\begin{tabular}{lll}
\hline Variables & $(\mathbf{n}=\mathbf{4 6})$ & $\%$ \\
\hline Age range & & \\
$1-5$ & 2 & 4.3 \\
$6-10$ & 6 & 13.0 \\
$11-15$ & 16 & 34.8 \\
$16-18$ & 22 & 47.8 \\
$\quad$ Mean \pm SD & $14.78 \pm 4.69$ & \\
Race & & \\
$\quad$ Malay & 44 & 95.7 \\
$\quad$ Others & 2 & 4.3 \\
Gender & & \\
$\quad$ Male & 21 & 45.7 \\
Female & 25 & 54.3 \\
Habits & & \\
Tobacco & 3 & 6.5 \\
Alcohol & 1 & 2.2 \\
\hline
\end{tabular}


HR-HPV in the oral cavity of women with cervical cancer, and their children

Four samples (5.71\%) from the oral cavity of women with cervical cancer showed positivity for HR-HPV using $\mathrm{HC}^{\circ}$ detection system, with $\mathrm{RLU} / \mathrm{CO}$ value being $>1$. Among the children, only $1(2.17 \%)$ sample was found to be positive for HR-HPV in the oral cavity. All the positive subjects showed clinically healthy oral mucosa without any lesions. Association of HPV in cervical cancer subjects was evaluated with age range, ethnicity, marital status, age when got married, number of children, pregnancy status, contraceptive pills usage, tobacco and alcohol habits, and any oral lesions. Chi square/Fisher's Exact test showed no significant association between HR-HPV infection with any of these variables $(p>0.05)$ (Table 3). As the percentage of HPV positivity was very low in children $(1 / 46,2.17 \%)$, no statistical analysis was performed.

\section{Discussion}

Various studies have been conducted to study the role of HPV in oral lesions and malignancies. However, the association of HPV between cervical and oral cavity remains unclear. Further, recent studies on mother-tochild transmission by perinatal infection with HPV have been inconclusive [15]. Considering the fact that almost all the cervical cancers are caused by HPV [22], this study was conducted to evaluate the prevalence of HRHPV in the oral cavity of women with cervical cancer, and their children. To our knowledge, this is the first study that has been carried out simultaneously in women with cervical cancers, and their children, to detect the presence of HR-HPV in their oral cavity.

Our results showed the prevalence of HR-HPV in oral cavity of women with cervical cancer to be quite low, with only 4 out of 70 subjects (5.71\%) testing positive for HR-HPV. The results found in this study were in concordance with the study done by Kellokoski et.al [23], which examined the cytological scrapings of oral mucosa in 309 women with genital HPV infections, by using dot blot hybridization and found oral HPV infection in only $3.8 \%$ women. Of these, only 2 had clinical lesions suggestive of HPV infection. In our study, all the HPV positive subjects had clinically normal oral mucosa. Another study, that was done to determine the HPV prevalence and concurrent infection in the cervix and oral cavity of 577 pregnant women, found $29 \%$ positivity in the cervix and $2.4 \%$ positivity in the oral cavity. No association was found between HPV positivity and its types detected in the cervix and oral cavity of these women, suggesting that self-inoculation was rare [24].

While recent studies have shown the presence of HRHPV in a faction of oral pre-malignant and malignant lesions, this may suggest a role of HPV in only a portion
Table 3 Association of HR-HPV in the oral cavity of women with cervical cancer, with variables

\begin{tabular}{|c|c|c|c|c|}
\hline Variable & $\mathbf{n}$ & HPV positive $n(\%)$ & $x^{2}$ & $p$ value $^{\mathrm{a}}$ \\
\hline \multicolumn{5}{|l|}{ Age range } \\
\hline $30-39$ & 4 & $0(0)$ & 4.06 & - \\
\hline $40-49$ & 18 & $0(0)$ & & \\
\hline $50-59$ & 22 & $3(13.6)$ & & \\
\hline $60 \&$ above & 26 & $1(3.8)$ & & \\
\hline \multicolumn{5}{|l|}{ Ethnicity } \\
\hline Malay & 58 & $2(3.4)$ & 3.22 & 0.133 \\
\hline Others & 12 & $2(16.7)$ & & \\
\hline \multicolumn{5}{|l|}{ Marital Status } \\
\hline Married & 59 & $4(6.8)$ & 0.79 & - \\
\hline Single & 1 & $0(0)$ & & \\
\hline Divorced & 2 & $0(0)$ & & \\
\hline Remarried & 8 & $0(0)$ & & \\
\hline \multicolumn{5}{|l|}{ Age when married } \\
\hline$<18$ years old & 33 & $1(3.0)$ & 0.84 & 0.352 \\
\hline$>18$ years old & 37 & $3(8.1)$ & & \\
\hline \multicolumn{5}{|l|}{ No of children } \\
\hline$<5$ & 26 & $2(7.7)$ & 0.30 & 0.476 \\
\hline$>5$ & 44 & $2(4.5)$ & & \\
\hline \multicolumn{5}{|l|}{ Pregnant } \\
\hline Yes & 2 & $0(0)$ & 0.13 & 0.888 \\
\hline No & 68 & $4(5.9)$ & & \\
\hline \multicolumn{5}{|l|}{ OCP usage } \\
\hline Yes & 24 & $0(0)$ & 2.21 & 0.178 \\
\hline No & 46 & $4(8.7)$ & & \\
\hline \multicolumn{5}{|l|}{ Tobacco usage } \\
\hline Yes & 3 & $0(0)$ & 0.19 & 0.836 \\
\hline No & 67 & $4(6.0)$ & & \\
\hline \multicolumn{5}{|l|}{ Alcohol consumption } \\
\hline Yes & 4 & $0(0)$ & 0.26 & 0.786 \\
\hline No & 66 & $4(6.1)$ & & \\
\hline \multicolumn{5}{|l|}{ Oral lesions } \\
\hline Yes & 6 & $0(0)$ & 0.398 & 0.693 \\
\hline No & 64 & $4(6.3)$ & & \\
\hline
\end{tabular}

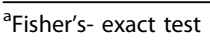

of oral malignancies, contrary to cervical region, where its association is noted in almost all the cervical malignancies [25]. This difference in HPV invasiveness could be due to various factors. Firstly, oral cavity is in direct contact with carcinogens present in tobacco and alcohol, making them the primary cause of oral carcinogenesis. This is not the case with cervical region, where there is no direct contact with these carcinogens. Secondly, the low prevalence of oral HPV infection might be due to the body's immune response, like immunoglobulin IgA and proteolytic enzymes in the saliva that protect the oral mucosa from viral infections [26]. Thirdly, antibodies produced by the body in response to initial infection, in this case cervical infection, might as well protect the 
body against further infections by the same virus on other sites. Fourthly, although the oral mucosal epithelium resembles the epithelium of the genital tract [27], antimicrobial action of saliva, along with its cleansing and lubricating properties, may reduce the possibility of virus entry into the oral epithelial cells by reducing the contact period of the virus with the oral mucosa [28]. Finally, considering the HPV detection method, although cytological scraping has many advantages, like being painless and non-invasive method, thus having better patient compliance compared to invasive procedures like biopsy, the disadvantage of this technique is that, in scrapings, basal and parabasal cells cannot be collected, which could lead to false negative results. Failure to collect the infected cells from basal layers might have also contributed to the low prevalence found in our study.

In contrast to our findings, a higher percentage $(15.4 \%$ and 29.4\%) of concurrent HPV infection between clinically normal oral mucosa and genital region, by using Southern blot and PCR procedures respectively, was obtained by Kellokoski et.al [29]. In another study, Badaracco et.al studied concurrent HPV infection in oral \& genital mucosa by using PCR based assay. Sixteen subjects positive for HPV (31.25\%) showed simultaneous genital \& oral cavity infections, while HPV type-specific concordance was detected in only 3 patients [10]. These differences in prevalence could be due to sensitivity of the assays used, and differences in sample size. Most of the previous studies were conducted using PCR based assays for HPV detection. PCR is highly sensitive with detection limits between 10-400 copies of HPV DNA resulting in detection of clinically insignificant viral levels which can be cleared by our own immune system. $\mathrm{HC} 2^{\circ}$, on the other hand, detects clinically relevant viral levels, that is 5000 copies and above [30]. At these viral levels, the probability of developing HR-HPV disease is high. Thus, prevalence obtained in studies that used PCR as HPV DNA detection assay will be higher as compared to $\mathrm{HC}^{\circ}{ }^{\circ}$. Moreover, $\mathrm{HC}^{\circ}$ detects only 13 types of HR-HPVs, while PCR based assays detect all types of HPVs.

Our study did not find any association of HPV in cervical cancer subjects with age range, ethnicity, marital status, number of children, tobacco or alcohol usage, contraceptive pills usage, or any oral lesions. This could be due to small percentage of positivity seen in our results and smaller sample size. Studies have shown that smoking has potential to alter oral epithelium, thus it has an influence on HPV expression in oral cavity [31]. However, as most of the subjects in this study (94.29\%) were non-smokers and non-alcoholics, any association with oral habits could not be established.

This study did not assess the presence of HPV in the genital regions of women with cervical cancers at the time of examining their oral cavity for HR-HPV. It is because this study was more focused on detecting HRHPV in the oral cavity, which might cause benign or malignant HPV related oral lesions in their future, rather than detecting concurrent infections in genital and oral regions, as reported in previously mentioned studies.

This study also aimed to detect the presence of HPV in oral cavity of the children of these women. Only 1 of the 46 children analysed was found to be positive for oral HR-HPV (2.17\%). Further questioning from this HR-HPV positive subject revealed that he was sexually active. Thus, the positivity could be, in part, due to the sexual activities rather than transmission from the mother. Similar to our results, Koch et al tested the presence of HPV in the anal region and the oral cavity of Danish children, aged 0 to 17 years, by PCR targeting the L1 region of the HPV genome. Only four of the 249 anal samples and one of 392 oral samples were found to be HPV positive. The authors concluded that ano-genital types of HPV are not transmitted by non-sexual routes, and that HPV infection mainly occurs later in life [32].

Children of older age groups were chosen for analysis in our study. This is because the infants were shown to have a higher percentage of oral HPV, which could be due to the result of surface contamination that might occur in these infants during childbirth rather than HPV infection per se [33]. This finding was reconfirmed by a recent study in which all the HPV-DNA positive newborns $(22.4 \%)$ at birth and at the end first month of life (6.1\%) became HPV-DNA negative by the age of 6 months [34]. Similarly, in 1986, Roman and Fife analysed the foreskins of 70 male infants undergoing routine circumcision for HPV type 6, 11, 16, and 18, by using dot blot hybridization and found HPV in $4 \%$ of the cases. The result suggested that neonates exhibit a relatively high incidence of exposure to HPV during or before birth. However, no correlation could be identified between mothers with abnormal pap smears and the HPV-positive foreskins [35]. Another recent study analysed 49 HPV DNA-positive pregnant women at the time of delivery and found $24.5 \%$ placentas had a positive result for HPV DNA. Eleven newborn were HPV DNA positive in samples from the nasopharyngeal or buccal and body or cord blood. Out of these, 5 cases (10.2\%) had HPV type-specific agreement between genital/placenta/newborn samples suggesting transplacental transmission [36]. Other studies have also supported the concept that maternal genital-tract HPV infection could cause other diseases like respiratory [37] and laryngeal papillomas [38] in children. Oral HPV prevalence in children has also been reported by few researchers $[39,40]$. Studies on newborn babies have detected a 
higher prevalence of $37 \%$ to $73 \%$ HPV DNA in the nasopharyngeal aspirates or buccal swabs [41-43].

Our study was cross-sectional as compared to several other studies which were longitudinal, starting from the HPV detection since the mother became pregnant, until the delivery or a few months after birth $[20,21,44,45]$. Based on our results, which showed very low HR-HPV positivity, we presume that even though there is a probability that HPV can spread to the oral cavities of children via vertical transmission, it will not persist until their adulthood. Most likely, the HPV DNA that detected right after their delivery was due to contamination, as suggested in other studies.

\section{Conclusion}

This study shows that there is low, if any, risk of HRHPV infection in oral cavity of women with cervical cancer. There were no relevant risk factors that contributed to the development of this infection. Further, our study suggests that there is very low risk for children of women with cervical cancer, to acquire and sustain HRHPV in their oral cavity until childhood or adolescence. More studies with bigger sample size are recommended to determine the relationship of HPV infection in these two areas. For more accurate evaluation of vertical transmission, long term follow-up studies should be conducted.

\section{Methods}

\section{Study Design and data collection}

This was a cross-sectional study that involved 70 women who were diagnosed to have cervical cancer, undergoing active treatment and routine follow up in Obstetrics and Gynaecology department or Oncology department of Hospital Universiti Sains Malaysia. A total of 46 children of these women, born only with vaginal delivery, were also examined. Only those children, who were born after the women were suspected or diagnosed of cervical cancer, were recruited in this study. Ethical approval was obtained from the Human Research Ethics Committee of Universiti Sains Malaysia. After obtaining the consent and explaining the procedure to each participant, questions about sociodemographics, marital status, reproductive history, tobacco or alcohol usage, contraceptive pills usage, oral and medical health status were asked using questionnaire provided to women at the time of enrollment. The questionnaire given to children was to inquire about their sociodemographic profile and habits. The children, who were older than 18 years of age, were married, or in any immunocompromised state like diabetes, were excluded from this study. Oral cavity of the subjects was also checked for any oral lesions, including HPV related oral lesions like papillomas, condylomas and focal epithelial hyperplasia, by a single oral medicine specialist to avoid inter-examiner variability.

\section{Sample collection and testing}

The buccal swabs were collected using DNAPap Cervical Sampler ${ }^{\mathrm{rt}}$, from right and left buccal mucosa by moving the brush in circular motions, and then kept in the transport medium. All the sample tubes were stored immediately in $-20^{\circ} \mathrm{C}$ until testing for HPV. All collected specimens were tested using Hybrid Capture $2^{\circ}$ (HC2) high-risk (HR) HPV DNA detection system located in the Department of Pathology, Universiti Sains Malaysia, and the procedure followed was according to the instruction of manufacturer. Digene $\mathrm{HC}^{\circ}$ detects $\mathrm{HR}$ HPV (Qiagen, U.S.A.) by using RNA probe cocktails to detect 13 HPV-HR which are HPV type-16, 18, 31, 33, $35,39,45,51,52,56,58,59$ and $68 . \mathrm{HC}^{\circ}$ technology is a nucleic acid hybridization assay for detection of HPV with signal amplification using microplate chemiluminescent detection. Light emitted is measured in terms of relative light units (RLUs) using Luminometer. RLU value is converted into ratio by the Cutoff value (5000 copies/ml). Any specimen with RLU/CO $\geq 1$ was considered positive.

\section{Statistical Analysis}

The prevalence of HPV in the oral cavity of cervical cancer subjects was analysed using estimation method. The association of HPV infection with risk factors (sociodemographic profile, marital status, reproductive history, tobacco and/or alcohol habits, contraceptive pills usage and any oral lesions) was analyzed using Chi square test/Fisher's exact test with software SPSS version 16.0.

\section{Acknowledgements}

The authors wish to acknowledge all the subjects who participated in this study. This study was supported by "Science fund" provided by MOSTI, Grant No- 305/PPSG/6113208.

\section{Author details}

'School of Dental Sciences, Universiti Sains Malaysia, Kubang Kerian, 16150, Kelantan, Malaysia. ${ }^{2}$ Infectious Disease Cluster, Advanced Medical and Dental Institute, Universiti Sains Malaysia, Bertam, 13200, Penang, Malaysia.

\section{Authors' contributions}

RS designed the research project and drafted the manuscript. TPK collected and processed the samples from the women with cervical cancer. SBR collected and processed the samples from the children of the women with cervical cancer. RS and TTH guided the bench work of the procedure. MI did the bench work for detecting HR-HPV in samples. RS and TTH critically reviewed the final manuscript. All authors read and approved the final manuscript.

\section{Competing interests}

The authors declare that they have no competing interests.

Received: 10 May 2010 Accepted: 16 June 2010 Published: 16 June 2010 


\section{References}

1. Hausen Z: Papillomavirus infections - a major cause of human cancers. Biochim Biophys Acta 1996, 2:F55-78

2. Ha KT, Kim JK, Lee YC, Kim CH: Inhibitory effect of Daesungki-Tang on the invasiveness potential of hepatocellular carcinoma through inhibition of matrix metalloproteinase-2 and -9 activities. Toxicol Appl Pharmacol 2004, 200:1-6

3. Syrjanen SM, Syrjanen KJ, Happonen RP: Hu man papiilomavirus (HPV) DNA sequences in oral precancerous lesions and squamous cell carcinoma demonstrated by in situ hybridization. J Oral Pathol 1988, 17:273-278.

4. de Villiers EM, Fauquet C, Broker TR, Bernard HU, Hausen Z: Classification of papillomaviruses. Virology 2004, 324:17-27.

5. Hildesheim A, Schiffman MH, Gravitt PE, Glass AG, Greer CE, Zhang T, Scott DR, Rush BB, Lawler P, Sherman ME: Persistence of type-specific human papillomavirus infection among cytologically normal women. $J$ Infect Dis 1994, 169:235-240.

6. Iwasawa A, Nieminen $\mathrm{P}$, Lehtinen M, Paavonen J: Human papillomavirus DNA in uterine cervix squamous cell carcinoma and adenocarcinoma detected by polymerase chain reaction. Cancer 1996, 77:2275-2279.

7. Miller $\mathrm{CS}$, Johnstone BM: Human papillomavirus as a risk factor for oral squamous cell carcinoma: a meta-analysis, 1982-1997. Oral Surg Oral Med Oral Pathol Oral Radiol Endod 2001, 91:622-635.

8. Saini R, Tang TH, Zain RB, Cheong SC, Musa KI, Saini D, Ismail AR, Abraham MT, Mustafa WM, Santhanam J: Significant association of highrisk human papillomavirus (HPV) but not of p53 polymorphisms with oral squamous cell carcinomas in Malaysia. J Cancer Res Clin Oncol.

9. Syrjanen S: Human papillomavirus infections and oral tumors. Med Microbiol Immunol 2003, 192:123-128.

10. Badaracco G, Venuti A, Di Lonardo A, Scambia G, Mozzetti S, Benedetti PP, Mancuso S, Marcante ML: Concurrent HPV infection in oral and genital mucosa. J Oral Pathol Med 1998, 27:130-134.

11. Chatterjee R, Mukhopadhyay D, Murmu N, Mitra PK: Correlation between human papillomavirus DNA detection in maternal cervical smears and buccal swabs of infants. Indian J Exp Biol 1998, 36:199-202.

12. Shibata DK, Arnheim N, Martin WJ: Detection of human papilloma virus in paraffin-embedded tissue using the polymerase chain reaction. J Exp Med 1988, 167:225-230.

13. Bosch FX, Castellsagué X, Muñoz N, de Sanjosé S, Ghaffari AM, González LC, Gili M, Izarzugaza I, Viladiu P, Navarro C, Vergara A, Ascunce N, Guerrero E, Shah KV: Male sexual behavior and Human Papillomavirus DNA: key risk factors for cervical cancer in Spain. J Natl Cancer Inst 1996, 88:1060-1067.

14. Mammas IN, Sourvinos G, Spandidos DA: Human papilloma virus (HPV) infection in children and adolescents. Eur J Pediatr 2009, 168:267-273.

15. Syrjanen S, Puranen M: Human papillomavirus infections in children: the potential role of maternal transmission. Crit Rev Oral Biol Med 2000, 11:259-274.

16. Sinal SH, Woods CR: Human papillomavirus infections of the genital and respiratory tracts in young children. Semin Pediatr Infect Dis 2005, 16:306-316.

17. Hajek EF: Contribution to the etiology of laryngeal papilloma in children. J Laryngol Otol 1956, 70:166-168.

18. Puranen M, Syrjanen $K$, Syrjanen S: Transmission of genital human papillomavirus infections is unlikely through the floor and seats of humid dwellings in countries of high-level hygiene. Scand J Infect Dis 1996, 28:243-246.

19. Kaye JN, Starkey WG, Kell B, Biswas C, Raju KS, Best JM, Cason J: Human papillomavirus type 16 in infants: use of DNA sequence analyses to determine the source of infection. J Gen Virol 1996, 77(Pt 6):1139-1143.

20. Tenti P, Zappatore R, Migliora P, Spinillo A, Belloni C, Carnevali L: Perinatal transmission of human papillomavirus from gravidas with latent infections. Obstet Gynecol 1999, 93:475-479.

21. Cason J, Mant CA: High-risk mucosal human papillomavirus infections during infancy \& childhood. J Clin Virol 2005, 32(Suppl 1):S52-58.

22. Walboomers JM, Jacobs MV, Manos MM, Bosch FX, Kummer JA, Shah KV, Snijders PJ, Peto J, Meijer CJ, Munoz N: Human papillomavirus is a necessary cause of invasive cervical cancer worldwide. J Pathol 1999, 189:12-19.

23. Kellokoski J, Syrjanen S, Yliskoski M, Syrjanen K: Dot blot hybridization in detection of human papillomavirus (HPV) infections in the oral cavity of women with genital HPV infections. Oral Microbiol Immunol 1992, 7:19-23.
24. Smith EM, Ritchie JM, Yankowitz J, Wang D, Turek LP, Haugen TH: HPV prevalence and concordance in the cervix and oral cavity of pregnant women. Infect Dis Obstet Gynecol 2004, 12:45-56.

25. Remmink AJ, Walboomers JM, Helmerhorst TJ, Voorhorst FJ, Rozendaal L Risse EK, Meijer CJ, Kenemans P: The presence of persistent high-risk HPV genotypes in dysplastic cervical lesions is associated with progressive disease: natural history up to 36 months. Int J Cancer 1995, 61:306-311.

26. Miletic ID, Schiffman SS, Miletic VD, Miller EA: Salivary IgA secretion rate in young and elderly persons. Physiol Behav 1996, 60:243-248.

27. Thompson IO, van der Bijl P, van Wyk CW, van Eyk AD: A comparative light-microscopic, electron-microscopic and chemical study of human vaginal and buccal epithelium. Arch Oral Biol 2001, 46:1091-1098.

28. Termine N, Giovannelli L, Matranga D, Perino A, Panzarella V, Ammatuna P, D'Angelo M, Campisi G: Low rate of oral human papillomavirus (HPV) infection in women screened for cervical HPV infection in Southern Italy: A cross-sectional study of 140 immunocompetent subjects. J Med Virol 2009, 81:1438-1443.

29. Kellokoski JK, Syrjanen SM, Chang F, Yliskoski M, Syrjanen KJ: Southern blot hybridization and PCR in detection of oral human papillomavirus (HPV) infections in women with genital HPV infections. J Oral Pathol Med 1992, 21:459-464.

30. Hybrid Capture 2 Technology. [http://www.qiagen.com/hpv/ hc2technology.aspx].

31. Syrjanen KJ: Papillomavirus infections, precancers and epidermoid cancers. Papillomaviruses in human pathology. Recent progress in epidermoid precancers New York: Raven PressMonsonego J 1990, 13-29.

32. Koch A, Hansen SV, Nielsen NM, Palefsky J, Melbye M: HPV detection in children prior to sexual debut. Int J Cancer 1997, 73:621-624.

33. Medeiros LR, Ethur AB, Hilgert JB, Zanini RR, Berwanger O, Bozzetti MC, Mylius LC: Vertical transmission of the human papillomavirus: a systematic quantitative review. Cad Saude Publica 2005, 21:1006-1015.

34. Rombaldi RL, Serafini EP, Mandelli J, Zimmermann E, Losquiavo KP: Perinatal transmission of human papilomavirus DNA. Virol J 2009, 6:83.

35. Roman A, Fife K: Human papillomavirus DNA associated with foreskins of normal newborns. J Infect Dis 1986, 153:855-861.

36. Rombaldi RL, Serafini EP, Mandelli J, Zimmermann E, Losquiavo KP: Transplacental transmission of Human Papillomavirus. Virol J 2008, 5:106.

37. Gerein V, Schmandt S, Babkina N, Barysik N, Coerdt W, Pfister H: Human papilloma virus (HPV)-associated gynecological alteration in mothers of children with recurrent respiratory papillomatosis during long-term observation. Cancer Detect Prev 2007, 31:276-281.

38. Alberico S, Pinzano R, Comar M, Zocconi E, Guaschino S: Juvenile laryngeal papillomatosis from an HPV-positive mother. A case report. Clin Exp Obstet Gynecol 1995, 22:243-246.

39. Kojima A, Maeda H, Kurahashi N, Sakagami G, Kubo K, Yoshimoto H, Kameyama Y: Human papillomaviruses in the normal oral cavity of children in Japan. Oral Oncol 2003, 39:821-828.

40. Summersgill KF, Smith EM, Levy BT, Allen JM, Haugen TH, Turek LP: Human papillomavirus in the oral cavities of children and adolescents. Oral Surg Oral Med Oral Pathol Oral Radiol Endod 2001, 91:62-69.

41. Fredericks BD, Balkin A, Daniel HW, Schonrock J, Ward B, Frazer $H$ : Transmission of human papillomaviruses from mother to child. Aust N Z J Obstet Gynaecol 1993, 33:30-32.

42. Pakarian F, Kaye J, Cason J, Kell B, Jewers R, Derias NW, Raju KS, Best JM Cancer associated human papillomaviruses: perinatal transmission and persistence. Br J Obstet Gynaecol 1994, 101:514-517.

43. Sedlacek TV, Lindheim S, Eder C, Hasty L, Woodland M, Ludomirsky A, Rando RF: Mechanism for human papillomavirus transmission at birth. Am J Obstet Gynecol 1989, 161:55-59.

44. Kaye JN, Cason J, Pakarian FB, Jewers RJ, Kell B, Bible J, Raju KS, Best JM: Viral load as a determinant for transmission of human papillomavirus type 16 from mother to child. J Med Virol 1994, 44:415-421.

45. Smith EM, Johnson SR, Cripe T, Perlman S, McGuinness G, Jiang D, Cripe L, Turek LP: Perinatal transmission and maternal risks of human papillomavirus infection. Cancer Detect Prev 1995, 19:196-205.

doi:10.1186/1743-422X-7-13

Cite this article as: Saini et al:: High-risk human papillomavirus in the oral cavity of women with cervical cancer, and their children. Virology Journal 2010 7:131. 